\title{
Role Of The Direct Teaching Method In The Academic Achievement Of Students In English At The Secondary Level
}

Ishtiaq Hussain, Kohat University (KUST), Pakistan Hafiz Inamullah, Kohat University (KUST), Pakistan

Muhammad Naseer-Ud-Din, Kohat University (KUST), Pakistan

Hafiz Hafizatullah, Kohat University (KUST), Pakistan

\begin{abstract}
The major objective of this study was to determine the role of the direct teaching method in the academic achievement of students in English at the secondary level. To achieve the said objective, the Solomon Four-Design pre-test/post-test equivalent group design" was considered to be the most useful design for this study. The pre-test was used to measure the achievement and was used only to equate the control and experimental groups. The experimental group was taught by the direct method, while the control group was taught by the traditional method. At the end of the treatment, it was concluded that the direct teaching method was more effective as a teachinglearning technique for English as compared to the traditional teaching method.
\end{abstract}

\section{INTRODUCTION}

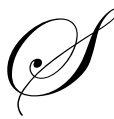

weet (1992) says, "Language is expression of ideas by means of which speech sounds are combined into words, words are combined into sentences and combination of sentences gives answers to ideas and thoughts".

English has always been rated high in Pakistan. In the past, it was treated as a compulsory subject from class 6 upwards in the public school system. It is being offered as a compulsory subject in English medium schools and is increasingly used as a medium of instruction. The private schools offer English as a subject in nursery classes. It means that students of public schools start studying English at the age of 11 years old, whereas the students of English medium schools start studying English at the age of 4 years old. Teaching English is important for the following reasons:

a. $\quad$ English is a means for understanding the foreign education.

b. English is the language of higher education.

c. English is the source of scientific and technological advancement.

d. It is the medium for international commerce, trade and communication (Richards, 1991).

Keeping in view the status of English, the government of Pakistan has made a decision to introduce English as a compulsory subject from the first level. The main objective of this study was to determine the role of direct teaching in the academic achievement of English students at the secondary level.

\section{REVIEW OF LITERATURE}

Every country has a national language, which is the means of expression of its thoughts, culture and covers the whole range of its social, cultural and official activities. In the present age of fast development in science and technology, there also arises the need for a foreign language to have access to modern scientific knowledge and for international communication. English is a means of international communication since it has assumed the role of world language. English is the only language, other than Urdu, that is understood, to some extent, in all parts of 
Pakistan. It is true that English has thrust its way into our lives and thoughts. It is the language of legislature, law courts, commercial, markets, social circles, technology and economics because most of the information is mostly available in English (Tanveer, 1998).

Learning a foreign language/second language is a complex process, as language is not just an act of putting meaningful words together. It needs a physical, intellectual and emotional response if we have to send or receive messages. Learning a foreign language involves a new culture and a new way of thinking, feeling and acting. The learner has to be fluent, accurate and meaningful (Graff, 1985).

Krashen and Terrel (1983) reported that language proficiency tests can be classified as tests of linguistic competence or communicative competence; that is, the ability to control pronunciation, morphology and syntax; communication and the ability to use language for specific purposes or some particular purpose.

Lionel (1985) reported that most textbooks used in reading were judged as inadequate. The main cause identified was that textbooks take a long time to produce; therefore, the selections they contain are often outdated by the time they reach the students. As a partial solution to the problem, the researcher suggested that the students should choose short readings as their assignments for the class.

\section{PROCEDURE}

In order to test the relative effectiveness of independent variables, i.e. an instructional paradigm (direct teaching), the choice of the most suitable design for this experiment was the basic step. A number of factors affect the internal and external validity of experimental designs. Relevant to internal validity, there are eight different factors, including history, maturation, testing, instrumentation, statistical regression, differential selection, experimental mortality, and selection maturation interaction. If these factors are not controlled in the design, they may produce adverse effects, which confound the effects of the independent variables as shown by the final test scores.

Whereas factors affecting internal validity operate on the scores derived from the dependent variables and therefore make the experiment poor as an experiment, factors affecting external validity operate upon the experimental treatments. Campbell and Stanley (1963) postulated four factors that jeopardize external validity.

"The Solomon Four-Design pre-test/post-test equivalent group design" was considered to be the most useful design for this study.

\section{POPULATION}

The aim of this study was to investigate the relative effectiveness of the direct teaching method in teaching English at the secondary level. Therefore, students studying at the secondary level constituted the population of this study.

\section{DELIMITATION OF THE STUDY}

The study was delimited to: English medium students of the $9^{\text {th }}$ class.

\section{SAMPLE}

Two sections (A and B) of the $9^{\text {th }}$ class of the Federal Government boys secondary school, Tarnol Islamabad (Urdu medium), and two sections (A and B) of the $9^{\text {th }}$ class of F.G. model school for boys' I-9/4 in Islamabad (English medium) were taken as the sample of this study. A sample of students from the Federal Government boys' secondary school, Naugazi Islamabad, was further divided into two groups, i.e. the experimental and control groups. Both groups were equated on the basis of pre-test scores and each group comprised of 30 students. 


\section{RESEARCH INSTRUMENTS}

In order to equate the control and experimental groups, a teacher-made pre-test was administered before the allocation of students to the experimental and the control groups. Immediately after the treatment was over, a teacher-made post-test was administered to subjects of both the experimental and the control groups. The purpose of this test was to measure the achievement of the students constituting the sample. The researcher constructed both tests after a thorough review of the techniques of test construction and related units of English.

Both the pre-test and post-test were almost parallel with the same difficulty level. Two chapters were taught before the start of the experiment; also given was a weight age of 25 percent for both tests. Each test was composed of multiple choice items, matching items pertaining to a combination of learning domains. These test items were taken from the selected five units of the $9^{\text {th }}$ class English textbook. During the experiment, these five units were taught to both the experimental and control groups and were intended to measure the learning outcomes.

\section{Reliability of Test}

The Solomon Four-Design pre-test/post-test equivalent group design was used for the treatment to test the reliability of the post-test scores obtained by the students who formed the sample of the study. The coefficient of reliability was determined using the Spearman-Brown Prophecy formula, estimating reliability from the comparable halves of the post-test and found the coefficient of correlation to be 0.75 .

\section{SELECTION AND TRAINING OF TEACHERS FOR EXPERIMENT}

One teacher from the Federal Government boys secondary school in Tarnol, Islamabad (Urdu medium) and one teacher from F G model school for boys I-9/4, Islamabad (English medium), both having equal qualifications, equal teaching experiences, and considerably equal teaching potential, were selected for teaching English to the control and experimental groups. The teacher who volunteered for the experimental groups was provided two weeks training in direct teaching; i.e. one week for reading and one week for speech.

\section{DATA COLLECTION}

During the experiment, two different treatment patterns were applied. The control groups were provided with a traditional routine situation in the classroom, while the experimental groups were provided with the direct teaching method. The experiment continued for six weeks and soon after the treatment was over, a post-test was administrated to measure the achievement of the sample subjects.

\section{ANALYSIS OF DATA}

Raw scores obtained from the pre-test and post-test were presented in tabular form for the purpose of interpretation. For the manipulation of data, the means, standard deviations, and the differences of means were computed for each group. Significance of difference between the mean scores of both the experimental and control groups on the variable of pre-test and post-test scores was tested at 0.05 levels by applying t-test. To examine the treatment affects for high and low levels of achievement of the two groups, the Solomon Four-Group design (2x2 analysis of variance) was applied. For this purpose, the students of the two groups were divided into two halves; i.e. high achievers (above the mean score) and low achievers (below the mean score). This division was made on the basis of pre-test scores.

\section{RESULTS AND DISCUSSION}

This section is confined to the analysis and interpretation of data obtained from the pre-test and post-test. Significance of difference between the mean scores of the experimental and control groups of both English and Urdu medium on the pre-test and post-test was found by applying t-test, analysis of variance, and the Solomon FourGroup design (analysis of variance). 


\section{CONCLUSIONS}

In the light of statistical analysis and the findings of this study, the following conclusions were drawn:

1. On a whole, the direct teaching method is more effective as a teaching-learning technique for English as compared to the traditional teaching method. Students in the direct teaching method outscored students working in the traditional learning situation.

2. Low achievers in direct teaching showed significant superiority over low achievers learning English by the traditional method. Thus, direct teaching was found to be a more effective method for teaching English to the low achievers, as compared to the traditional method of teaching.

3. High achievers, whether they were taught English by the direct or traditional method, retained learned material at the same rate.

4. Low achievers taught English by the direct method retained more material, as compared to low achievers taught by the traditional method of teaching. Therefore, the direct teaching seemed to be a more effective teaching-learning technique for low achievers.

5. English textbooks, mostly written for direct teaching, were taught through the traditional method. The results were not good because teachers were not conversant with the direct method.

\section{REFERENCES}

1. Campbell, D. \& K. Stanley. (1963). Experimental and Quasi-Experimental Designs for Research on Teaching, in Handbook of Research on Teaching. Rand Mc Nelly and Company, Chicago, USA. (p. 175).

2. Graff, W. (1985). Language and Learning Principles. . Longmans Green and Co LTD. London, UK. (pp. 60-67).

3. Krashen, L. \& Terrell, J. (1983). Second Language Acquisition Learning Skills Paragons. New York, USA. (p. 23).

4. Lionel, M. (1985). Students Choice: Short Reading for the ESL, Classroom English Teaching Forum DC. Vol No-1 Washington, USA. (pp. 87-90).

5. Richards, J. (1991). The Context of Language Teaching. Cambridge University Press, London, UK. (pp. 49, 520).

6. Sweet, S. (1992). Language and the Study of Language, 4th edition. Merrill Publishing Company New York, USA. (p. 45).

7. Tanveer, M. (1998). Education and the Development of Muslim Nationalism in Pre-Partition India. University of California. (pp. 45-49). 